\title{
A NOTE ON THE CAPTURE OF PREY BY SEPIA OFFICINALIS L.
}

\author{
By Douglas P. Wilson
}

Naturalist at the Plymouth Laboratory

(Plates VI and VII)

There are various short and incomplete accounts of the capture of prey by Sepia scattered throughout the literature (Grimpe, I928; Hertling, I929; Holmes, I940, are all typical and fairly recent), but I have not found any really satisfactory figures. Those I have seen are little better than rough sketches (Grimpe, I928, p. 372; Naef, 1923, text-fig. 304 b; Tompsett, 1939, plate i, fig. 2) and there do not appear to be any photographs at all. A few observations, and some photographs I have taken recently should therefore be of interest, especially as the photographs reveal some points that do not appear to have attracted attention previously. The final stages of the capture take place so rapidly that the eye fails to observe the details, whereas photographs can be studied at leisure afterwards.

The specimen of Sepia that forms the subject of these pictures was of medium size with a shell about $\mathrm{I} 2 \mathrm{~cm}$. long. It had been living in a tank, with others of about the same size, for several months, during which time it had been fed on living prawns. It was-photographed in mid-November when the water temperature was $12.5^{\circ} \mathrm{C}$. (in a later paper I shall show that below about $\mathrm{II}^{\circ} \mathrm{C}$. Sepia often ceases to feed). The photographs were taken by flashlight on two evenings between 7 and 8.30 p.m., the tank being lit, for viewing purposes, by a 100 W. bulb in a reflector above one end (the left side in the pictures). Each photograph was taken at $\frac{1}{100} \mathrm{sec}$. with one Baby Sashalite bulb and a synchronizer of my own design, the shutter being released electrically. In Pl. VII, figs. 2 and 3 , two photoflood lamps were added to give better illumination on the shadow side, and these were also synchronized with the shutter so that they were switched on to reach maximum intensity just as the latter was released. Thus the cuttlefish was not influenced by the brilliance of their light before the exposure was made. At the flash, and the simultaneous switching on of the photofloods, the Sepia would momentarily hesitate, giving time for the prawn to be rescued so that the apparatus might be set for another exposure. Once, however, the cuttlefish had actually seized its prey it would not let go and would not show interest in another prawn placed in the tank. In the aquarium, before the war, I have often seen large Sepia catch two or three prawns in quick succession and eat them all, and Dr Anna M. Bidder tells me she has recorded an even larger number of crabs and prawns taken one after another during an hour or so. 
When a prawn or a crab (Portunus depurator was often used to feed Sepia at Plymouth) is first introduced, the cuttlefish, which is probably resting quietly on the bottom partially covered with sand, immediately takes notice. The eyes open a little, and colour changes begin to shimmer rapidly over arms and back. Often a deep flush spreads over the arms and around the eye region, extending sometimes on to the back, as the Sepia rises slightly and turns to face its prey. Colour reactions vary a little between individuals and in the same individual from time to time, but broadly are always the same. They have been well described by Holmes (1940, p. 28), who gives a good brief account of the hunting. The Sepia swims stealthily towards its victim, manoeuvring, if it be a crab, to approach from behind, for very rarely will it seize a crab from in front; prawns are taken from any angle. With undulations of the lateral fins and gentle backwardly directed jets from the siphon (Russell \& Steven, 1930) it endeavours to approach within range. At the same time the eight arms are stretched out towards the victim, the upper pair frequently being raised vertically, or curled upwards in the form of an $\mathrm{S}$, and depressed again, the lower pair directed slightly downwards and often parted to each side. Colour changes pass rapidly over them. The pale tentacles are partially extended in advance of the arms (Pl. VI, fig. I). Whilst Holmes may be partly right in suggesting that 'the colour movements... serve to distract the attention of the prey from the tentacles which spring out towards it', I have no doubt that many crabs and prawns do watch these tentacles and stand ready to dodge at the moment they are shot forward. Until that moment they may not shift their position, though a crab will circle, if it can, to keep its face and claws towards its enemy. I have watched a prawn in a small tank successfully dodge five times in succession, only to be caught at the sixth attempt. That last time it was not in such a favourable position for escaping, having got itself into a top corner of the tank close up against the water surface, the Sepia, meanwhile, approaching from the middle of the tank and shooting obliquely upwards. In a large tank crabs and prawns often get away, and this must be a regular occurrence in the sea once the enemy has been sighted; surprise must play a big part in aiding Sepia to catch its food. As it lies on the bottom, partially covered in sand, prey must often approach closely, unaware of its presence until too late. However, there is little doubt that Sepia does at times chase its prey, especially when really hungry, as can be seen in a large tank when crabs are dropped in many feet away and the Sepia rush towards them. When well fed, cuttlefish may be content to wait until the prey approaches closely.

Pl. VI, fig. 2, is an example of a prawn successfully escaping. It had stood still as the cuttlefish approached with outstretched tentacles and then, as they were suddenly shot forward, it jumped violently upwards with a sharp flexing of the abdomen. The switch operating the photographic mechanism had been thrust down into contact the instant the tentacles were shot forwards and as the prawn jumped. The whole process had taken place too quickly for the eye to 
follow, but the photograph suggests that the cuttlefish was rushing forwards when the ends of the tentacles struck the ground after missing the prawn and, overrunning them, had thrown them into loops. The siphon is directed backwards and there is a scurry of gravel particles under the Sepia, appearing in a cloud behind. Evidently a powerful backward jet of water had brought about a sudden forward movement of the cuttlefish which was sufficiently rapid to blur at $\frac{1}{100} \mathrm{sec}$. The arms are bent around to each side ready to receive the prey, which has, however, escaped, and, in the sea, might reach a safe distance before the Sepia has recovered itself. A moment later the tentacles were retracted and the cuttlefish retreated in the opposite direction, but this direction may have been influenced by the sudden bright flash in front of it.

Pl. VI, fig. 3, and Pl. VII, fig. 2, are photographs of the successful capture of a prawn. They were taken on succeeding evenings, and in both the shutter has exposed the plate at about the very instant of contact of the tentacles with the prey. The sucker-bearing heads are blurred, indicating the rapidity of the movement and, whilst it is difficult to be quite certain, it does appear as though the distal ends of the tentacles were travelling more rapidly than the proximal. At any rate this is a point worth future investigation. The extended tentacles are relatively straight from their sockets to the prawn, which in one picture is well blurred, probably indicating an escape movement, although there is the possibility that it is the beginning of the sudden pull back to the mouth of the Sepia. In the other picture the head of the prawn is sharp and the tail blurred in a way that suggests violent flexure in an attempt to escape. In both instances the prawn is held by the middle region of the body; this seems to be usual. The pictures show the siphon to be curled back, and in Pl. VII, fig. 2, there is a slight disturbance of particles in the tail region, which may, however have been due to currents induced by the lateral fins; the scurry in Pl. VI, fig. 2, seems to have been too violent to be accounted for solely by the action of the fins. At the same time as the tentacles are shot out the head is craned forward on the neck (compare with P1. VII, fig. 3). The arms are suddenly curled back ready to receive the prey.

It would be interesting to know how protraction of the head is brought about. Tompsett (I939) mentions only retractor muscles to the head in the neck region. The drawing in his pl. i, fig. 2 , shows something of the outstretched neck, but nothing is said about it in the text. The swift protraction of the tentacles is almost certainly brought about by their internal musculature which includes numerous circular and radiating fibres in addition to longitudinal muscles (Tompsett, I939). A large nerve runs down the centre of each tentacle to the tip.

A prawn is held across the mouth with the head to one side and the tail to the other and with the back towards the beak. A prawn that is caught in such a way that the ventral side is towards the mouth is turned round in the arms. It is then bent head to tail and bitten into about the region of the main dorsal 
arch of the body. A crab is held with the back of the carapace to the beak in such a way that the claws are unable to nip the cuttlefish anywhere. I have occasionally seen crabs, which had been badly secured, manage to nip the arms; they were immediately released and made good their escape. The prey is soon dead and is almost wholly consumed, very few fragments being left. This is in contrast to Eledone and Octopus which discard most of the shells of the crabs they eat.

Sepia relies on its eyes when hunting and probably receives little or no help from its other sense organs. The olfactory pits, situated behind the eyes, function in all likelihood as osphradia (Tompsett, 1939) and have nothing to do with the capture of prey. The reliance on sight is emphasized by the fact that on two occasions when taking these photographs the cuttlefish directed its tentacles to one side of the prawn, hitting the glass some distance away from the intended victim. This it appears to be about to do in Pl. VI, fig. I, but it was startled into retreat by the flash which exposed the plate before the tentacles had been shot out. It will be remembered that the photographs were taken after dark with a strong viewing light above and directed into the tank, the laboratory outside being dimly lit. Under these conditions the Sepia would see a good reflected image of the prawn in the glass and evidently was unable to distinguish it from the real thing.

Whilst in captivity the food of Sepia consists largely of living prawns, shrimps and small crabs, particularly Portunus depurator, which has a relatively thin shell. I have also seen small fishes taken whilst they were swimming (Hertling (1929) records the capture of Ammodytes though Grimpe (1928) says he has never seen free-swimming prey caught). When very hungry after a period of starvation Sepia will resort to cannibalism, the larger individuals eating the smaller. This is especially liable to happen in warm summer weather when their metabolism is at a high level and their feeding requirements correspondingly great.

\section{REFERENCES}

GRIMPE, G., I928. Pflege, Behandlung und Zucht der Cephalopoden für zoologische und physiologische Zwecke. Handbuch biol. Arbeitsmeth., Abt. Ix, Teil 5, Heft 3, pp. $331-402$.

HertLING, H., I929. Eine Sepia officinalis im Aquarium der Biologischen Anstalt auf Helgoland. Zool. Anz., Bd. 86; pp. 34-8.

Holmes, W., I940. The colour changes and colour patterns of Sepia officinalis L. Proc. Zool. Soc. London, Ser. A, Vol. I Io, pp. I7-35.

Naef, A., I923. Die Cephalopoden. Fauna Flora Golf. Neap., Mono. 35.

Russell, F. S. \& Steven, G. A., I930. The swimming of cuttlefish. Nature, Vol. I25, p. 893 .

TompsetT, D. H., 1939. Sepia. L.M.B.C. Memoir, xxxiI. 


\section{EXPLANATION OF PLATES VI AND VII}

\section{Plate VI}

Fig. I. Sepia officinalis approaching a prawn with outstretched arms and protruded tentacles. A deep flush extends over the upper surface of the arms and face.

Fig. 2. Prawn escaping by a quick upward jump, the tentacles of the Sepia missing and hitting the ground. The Sepia is rushing forward with outstretched neck and arms parted to each side.

Fig. 3. Prawn successfully seized. The head of the Sepia is craned forwards on the neck and the arms are parted to each side ready to receive the prey when it is drawn back on to them.

All exposures by synchronized flashlight at $\frac{1}{100} \mathrm{sec}$.

\section{Plate VII}

Fig. I. Sepia officinalis moving after a prawn which is out of sight on the right. In this picture the two upper arms are partially raised in the form of an S. A deep flush spreads over the upper surface of the arms and face and on to the back which is sprinkled over with sand.

Fig. 2. The prawn is seized as it is about to move away (for an alternative interpretation see text). The head is craned forwards on the neck and the arms are parted to each side ready to receive the prey.

Fig. 3. The prawn was caught a few minutes before and the Sepia is settling itself down to eat it.

All exposures by synchronized flashlight at $\frac{1}{100} \mathrm{sec}$. 